\title{
Evaluation of Growth Performance, Carcass Characteristics and Meat Quality of Shaziling Pigs and its Hybrids Crossbred with Berkshire Pigs
}

\begin{abstract}
Background: The Chinese Shaziling pig is representative of good meat quality but has been scarcely utilized on commercial farms because of the unpleasing growth and carcass traits.

Methods: The growth performance, carcass characteristics, meat quality and fatty acids profile were analyzed among (Berkshire $\times$ Shaziling $\times$ (Berkshire $\times$ Shaziling) $(B S \times B S), B S \times S$, Shaziling $(S \times S)$ and $S \times B S$ pigs

Result: BS $\times$ BS pigs exhibited higher growth rate and superior carcass performance. Each breed possessed desirable meat quality, as evidenced by moderate $\mathrm{pH}$, color score, IMF content and shear force value, among which the performance of $S \times B S$ pigs was prominent. Take account of the contents of SFAs, MUFAs, PUFAs and PUFAs/SFAs value, the eating quality of $S \times B S$ pigs was favorable and the meat of BS $\times$ BS pigs, by contrast, was helpful for human health with advanced nutritional value. In summary, BS $\times$ BS pigs is more effective for commercial development of Shaziling pigs and providing healthy pork products.
\end{abstract}

Key words: Carcass characteristics, Crossbreeds, Growth performance, Meat quality, Shaziling pigs.

\section{INTRODUCTION}

The growth performance, carcass characteristics and meat quality in pigs are considerable economic traits. It is well known that the western pig breeds Berkshire, Duroc, Yorkshire and Landrace, characterized by superior growth rate and lean percentage, represent the majority of pig breeds on the market. However, the accompanying defect is the decline in pork quality (Keenan, 2016). With the promotion of people's life quality, the focal point of meat consumption demand has gradually altered from 'quantity' to 'quality' and therefore, improvement of meat quality has dramatic effect on pig industry (Ilavarasan and Abraham 2018).

The Shaziling pig, an indigenous Chinese breed mainly reared in Hunan province, is representative of slow growth rate, poor feed conversion and low lean percentage, in spite of the properties of good meat quality and strong adaptability (Chen et al., 2021; Yang et al., 2016). Given the outstanding characteristics of western and indigenous pig breeds, there is a rising trend to improve the efficiency of commercial pig production with the advantages of both type breeds by crossbreeding systems (Guo et al., 2017; Jiang et al., 2011).

In the current study, the Berkshire $\times$ Shaziling crossbred pigs were used to form the primary population and then the intercross offspring was produced (named as BS $\times$ BS). The crossbreeds of BS $\times S, S \times B S$ and Shaziling pigs (named as $S \times S)$ were cultivated, respectively. The growth performance, carcass trait, meat quality and fatty acids (FAs) profile were examined. This study provides the scientific basis for industrial improvement of Shaziling pigs and exploitation of special pork products.
Hunan Institute of Animal and Veterinary Science, Changsha 410131, P.R. China.

Corresponding Author: Y.L. Peng, Hunan Institute of Animal and Veterinary Science, Changsha 410131, P.R. China.

Email: Ylpeng_1965@163.com

How to cite this article: Chen, C., Deng, Y., Ren, H.B., Zhu, J., Cui, Q.M., Hu, X.G. and Peng, Y.L. (2021). Evaluation of Growth Performance, Carcass Characteristics and Meat Quality of Shaziling Pigs and its Hybrids Crossbred with Berkshire Pigs. Indian Journal of Animal Research. DOI: 10.18805/IJAR.BF-1419.

Submitted: 09-08-2021 Accepted: 22-10-2021 Online: 06-11-2021

\section{MATERIALS AND METHODS}

The experiment was performed in accordance with the guidelines for the Animal Care and Use Committee of Hunan Institute of Animal and Veterinary Science.

\section{Animals and experimental design}

A total of 80 healthy pigs (50\% castrated male and $50 \%$ female) with similar initial body weight were randomly selected including BS $\times$ BS, BS $\times S, S \times S$ and $S \times B S$. Each group consisted of two pens with ten pigs each and the pigs were raised under similar conditions. All pigs were hand-fed two times daily and water was provided ad libitum. The feeding experiment lasted for 98 days after 7 days of adaptation period. The ingredient and chemical composition of the experimental diet offered to all pigs was presented in Supplementary Table 1.

\section{Growth performance}

The initial body weight and final body weight were recorded 
Supplementary Table 1: Ingredient and chemical composition of experimental diet.

\begin{tabular}{lcc}
\hline \multicolumn{3}{c}{ experimental diet. } \\
Item & $\begin{array}{c}\text { Growing } \\
(30 \mathrm{~kg}-60 \mathrm{~kg})\end{array}$ & $\begin{array}{c}\text { Fattening } \\
(60 \mathrm{~kg})\end{array}$ \\
\hline Ingredient, \% & & \\
Paddy & 50.40 & 50.50 \\
Corn & 5.30 & 7.90 \\
Soybean meal & 11.90 & 5.00 \\
Rice & - & 10.00 \\
Wheat bran & 6.00 & 4.60 \\
Oil bran & 20.00 & 18.00 \\
Soybean oil & 2.40 & - \\
Premix & \\
Total & 4.00 & 4.00 \\
Chemical composition & 100.00 & 100.00 \\
Digestible energy, MJ kg ${ }^{-1}$ & 13.02 & \\
Crude protein, \% & 13.51 & 12.71 \\
Calcium, \% & 0.60 & 11.00 \\
Total phosphorus, \% & 0.64 & 0.62 \\
Available phosphorus, \% & 0.18 & 0.76 \\
Lysine, \% & 0.75 & 0.17 \\
Methionine, \% & 0.22 & 0.60 \\
\hline
\end{tabular}

Supplied, per kilogram of diet: $19.8 \mathrm{mg} \mathrm{CuSO} \cdot 5 \mathrm{H}_{2} \mathrm{O} ; 0.20 \mathrm{mg} \mathrm{KI}$; $400 \mathrm{mg} \mathrm{FeSO} \cdot 7 \mathrm{H}_{2} \mathrm{O} ; 0.56 \mathrm{mg} \mathrm{NaSeO} ; 359 \mathrm{mg} \mathrm{ZnSO} \cdot 7 \mathrm{H}_{2} \mathrm{O} ; 10.2$

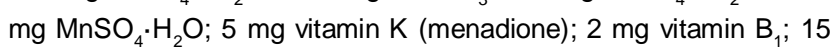
mg vitamin $B_{2} ; 30$ ig vitamin $B_{12} ; 5400 \mathrm{IU}$ vitamin $A ; 110 \mathrm{IU}$ vitamin $\mathrm{D}_{3} ; 18 \mathrm{IU}$ vitamin $\mathrm{E} ; 80 \mathrm{mg}$ choline chloride; $100 \mathrm{mg}$ Fungicide.

in each pig and feed intake was also recorded for determining the average daily gain (ADG) and feed intake to body gain ratio (Feed/Gain).

\section{Slaughter procedure}

At the end of the experiment, pigs with medium weight per pen were selected and the slaughter weights of BS $\times$ BS $(n=6), B S \times S(n=4), S \times S(n=4)$ and $S \times B S(n=4)$ pigs ( $50 \%$ castrated male and $50 \%$ female) were recorded. Pigs were slaughtered at a local commercial slaughter house.

\section{Carcass measurements}

Carcass composition was determined following the Technical Regulation for Testing of Carcass Traits in Lean-type Pig (NY/T 825-2004) and the loin-eye area of longissimus dorsi muscle at the last rib was determined by measuring its width and height (GB/T 8467-1987). The left side of carcass was then divided into lean, fat, skin and bone tissue and tissue percentage was individually calculated.

\section{Meat quality measurements}

Longissimus thoracis (LT), longissimus lumborum (LL) and psoas muscles on the left side of carcass were immediately harvested within $1 \mathrm{~h}$ postmortem. The meat quality was assessed according to the methods represented in technical code of practice for pork quality assessment (NY/T 8212019) and determination of meat tenderness-shear force method (NY/T 1180-2006). In LT sample, $\mathrm{pH}$ values at $1 \mathrm{~h}$
$\left(\mathrm{pH}_{1}\right)$ and $24 \mathrm{~h}\left(\mathrm{pH}_{24}\right)$ postmortem were recorded, meat color was exhibited as $\mathrm{L}^{*}, \mathrm{a}^{*}$ and $\mathrm{b}^{*}$. Marbling score was evaluated based on the National Pork Producers Council (NPPC, 2000). In LL sample, intramuscular fat (IMF) content and drip loss were measured according to the methods described previously (Latimer, 2012; Lee et al., 2012). For evaluating water loss, meat slice was put on the platform of unconfined pressure instrument, maintaining pressure of $35 \mathrm{~kg}$ for 5 min. For cooking yield, psoas muscle was weighed and steamed for $30 \mathrm{~min}$, then the sample was hung at room temperature for $20 \mathrm{~min}$ and weighed. Inosine monophosphate (IMP) concentration was determined using the method as described in detail (Li et al., 2018).

\section{Determination of FAs composition}

The composition of FAs in LL sample was detected according to the methods previously described (Liu et al., 2015) and the content of individual FA was represented with percentage of total FAs.

\section{Statistical analysis}

Experimental data were analyzed by one-way ANOVA procedure with SPSS 20.0 software. Duncan method was used for multiple comparison and significance test. Result was expressed as mean and $\mathrm{SEM}, \mathrm{P} \leq 0.05$ was considered significant.

\section{RESULTS AND DISCUSSION \\ Growth performance}

The final body weight in BS $\times$ BS pig was significantly higher $(P<0.01)$ than that in Shaziling pigs and $B S \times B S$ pigs had the highest ADG $(P<0.01)$ and lowest Feed/Gain (Table 1). The result is consistent with the former studies that the growth performance of crossbred pigs was superior to the indigenous pigs (Franco et al., 2014; Gopinathan and Usha 2011; Jiang et al., 2011; Touma and Oyadomari 2020). Meanwhile, BS $\times$ BS pigs had an advantage of growth performance in comparison with BS $\times S$ and $S \times B S$ pigs. This phenomenon may be explained by the fact that BS $x$ BS pigs contained higher proportion of Berkshire gene.

\section{Carcass characteristics}

Compared with other three groups, BS $\times$ BS pigs exhibited advantages in carcass parameters including carcass length, average backfat thickness, loin-eye area and lean percentage, although not all the differences were to the level of statistical significance (Table 2), indicating that BS $\times$ BS pigs possess excellent carcass characteristics.

\section{Meat quality}

Considerable differences were observed in $a_{1}{ }^{*}$ value, color score and shear force among different groups (Table 3). Specifically, $a_{1}{ }^{*}$ value was significantly lower $(P<0.01)$ in $\mathrm{BS} \times \mathrm{S}$ pigs than that in other pig breeds and consumers may be more willing to accept the meat of BS $\times$ BS, Shaziling and $S \times$ BS pigs (Corlett et al., 2021). In addition, color score ranged from 3.13 to 3.88 , indicating that all breeds had good meat color (NPPC, 2000). IMF contents in four 
groups were all higher than $2 \%$, which could meet the demand for pork products with pleasing taste quality (Chen et al., 2016). Furthermore, compared color score, IMF content and shear force value among $B S \times S$, Shaziling and $S \times$ BS pigs, the results showed that color score was $3.13,3.50$ and 3.88 and IMF content was 2.55, 3.90 and 4.58 and shear force value was $14.06,7.60$ and 6.42 , respectively, suggesting that the performance of $S \times B S$ pigs was prominent and the influence of paternity maybe greater than that of maternity in terms of the three indicators. In summary, each pig breed possessed desirable meat quality.

\section{FAs composition}

In four groups, the predominant components in FAs were C18:1n-9c, C16:0, C18:0 and C18:2n-6c, which accounted for $90 \%$ of all the FAs. Additionally, monounsaturated fatty acids (MUFAs) and saturated fatty acids (SFAs) were the most abundant components (Table 4). These results are in

Table 1: Growth performance of BS $\times$ BS, BS $\times S, S \times S$ and $S \times B S$ pigs.

\begin{tabular}{|c|c|c|c|c|c|c|}
\hline Item & $B S \times B S$ & $B S \times S$ & $S \times S$ & $S \times B S$ & SEM & $p$-value \\
\hline Initial body weight, kg & 32.40 & 30.19 & 31.02 & 32.27 & 0.35 & 0.08 \\
\hline Final body weight, kg & $93.24^{\mathrm{a}}$ & $77.06^{\mathrm{b}}$ & $76.94^{\mathrm{b}}$ & $88.12^{a}$ & 1.22 & $<0.01$ \\
\hline$A D G, g^{-1}$ & $607.93^{a}$ & $523.71^{\mathrm{b}}$ & $472.42^{c}$ & $534.69^{b}$ & 8.52 & $<0.01$ \\
\hline Feed/Gain & 3.83 & 3.90 & 4.08 & 3.93 & & \\
\hline
\end{tabular}

a-c Within a row, values with different superscript letters differ $(P<0.05)$.

Table 2: Carcass characteristics of $B S \times B S, B S \times S, S \times S$ and $S \times B S$ pigs.

\begin{tabular}{|c|c|c|c|c|c|c|}
\hline Item & $\mathrm{BS} \times \mathrm{BS}$ & $\mathrm{BS} \times \mathrm{S}$ & $S \times S$ & $\mathrm{~S} \times \mathrm{BS}$ & SEM & $\mathrm{p}$-value \\
\hline Slaughter weight, kg & $92.23^{a}$ & $88.30^{\mathrm{a}}$ & $83.43^{b}$ & $90.85^{\mathrm{a}}$ & 1.03 & $<0.01$ \\
\hline Carcass weight, kg & $67.31^{\mathrm{a}}$ & $64.38^{\mathrm{ab}}$ & $61.13^{\mathrm{b}}$ & $66.63^{a}$ & 0.79 & $<0.01$ \\
\hline Dressing percentage, \% & 72.98 & 72.89 & 73.26 & 73.35 & 0.46 & 0.95 \\
\hline Carcass straight length, cm & 90.92 & 86.75 & 87.63 & 86.75 & 0.75 & 0.09 \\
\hline Carcass slanting length, cm & 78.58 & 75.88 & 76.13 & 76.00 & 0.54 & 0.16 \\
\hline Average backfat thickness, $\mathrm{cm}$ & 3.22 & 3.51 & 3.81 & 3.86 & 0.12 & 0.13 \\
\hline Skin thickness, cm & 0.54 & 0.49 & 0.51 & 0.49 & 0.02 & 0.90 \\
\hline Loin-eye area, $\mathrm{cm}^{2}$ & 25.16 & 24.56 & 19.53 & 23.63 & 0.97 & 0.17 \\
\hline Ham percentage, \% & 26.38 & 25.79 & 26.11 & 27.12 & 0.21 & 0.17 \\
\hline Lean percentage, \% & $46.79^{a}$ & $43.32^{\mathrm{ab}}$ & $40.66^{b}$ & $41.41^{b}$ & 0.93 & 0.04 \\
\hline Fat percentage, \% & $27.74^{\mathrm{b}}$ & $30.68^{a b}$ & $33.63^{a}$ & $33.74^{a}$ & 0.94 & 0.03 \\
\hline Skin percentage, \% & 13.51 & 15.02 & 15.10 & 12.51 & 0.50 & 0.24 \\
\hline Bone percentage, \% & 11.97 & 10.98 & 10.61 & 12.34 & 0.29 & 0.14 \\
\hline
\end{tabular}

a, b Within a row, values with different superscript letters differ $(P<0.05)$.

Table 3: Meat quality of BS $\times$ BS, BS $\times S, S \times S$ and $S \times B S$ pigs.

\begin{tabular}{|c|c|c|c|c|c|c|}
\hline Item & $\mathrm{BS} \times \mathrm{BS}$ & $B S \times S$ & $S \times S$ & $S \times B S$ & SEM & $p$-value \\
\hline $\mathrm{pH}_{1}$ & 6.51 & 6.44 & 6.51 & 6.42 & 0.05 & 0.88 \\
\hline $\mathrm{pH}_{24}$ & 5.76 & 5.70 & 5.81 & 5.76 & 0.04 & 0.84 \\
\hline $\mathrm{L}_{1}{ }^{*}$ & 33.49 & 34.23 & 32.16 & 33.26 & 0.46 & 0.54 \\
\hline$a_{1}^{*}$ & $5.03^{a}$ & $3.70^{\mathrm{b}}$ & $4.88^{a}$ & $4.59^{a}$ & 0.16 & $<0.01$ \\
\hline$b_{1}^{*}$ & 1.16 & 1.04 & 0.66 & 0.95 & 0.09 & 0.27 \\
\hline $\mathrm{L}_{24}{ }^{*}$ & 40.47 & 43.16 & 36.75 & 39.70 & 0.94 & 0.15 \\
\hline$a_{24}{ }^{*}$ & 4.99 & 4.45 & 5.67 & 6.22 & 0.36 & 0.40 \\
\hline$b_{24}^{*}$ & 1.20 & 1.51 & 0.58 & 1.55 & 0.20 & 0.36 \\
\hline Color score & $3.33^{b c}$ & $3.13^{c}$ & $3.50^{\mathrm{b}}$ & $3.88^{a}$ & 0.08 & $<0.01$ \\
\hline IMF, \% & $2.23^{c}$ & $2.55^{\mathrm{bc}}$ & $3.90^{\mathrm{ab}}$ & $4.58^{a}$ & 0.32 & 0.01 \\
\hline IMP, $\mathrm{mg} \mathrm{g}^{-1}$ & 2.08 & 2.07 & 2.00 & 1.92 & 0.07 & 0.85 \\
\hline Drip loss, \% & 1.18 & 1.07 & 0.94 & 0.68 & 0.10 & 0.33 \\
\hline Water loss, \% & 11.36 & 10.12 & 8.94 & 10.65 & 0.43 & 0.28 \\
\hline Cooking yield, \% & 64.19 & 66.07 & 67.68 & 68.99 & 0.77 & 0.10 \\
\hline Shear force, $\mathrm{N}$ & $10.42^{\mathrm{ab}}$ & $14.06^{\mathrm{a}}$ & $7.60^{b}$ & $6.42^{b}$ & 1.00 & 0.03 \\
\hline
\end{tabular}

a-c Within a row, values with different superscript letters differ $(P<0.05)$. 
Evaluation of Growth Performance, Carcass Characteristics and Meat Quality of Shaziling Pigs and its Hybrids Crossbred...

Table 4: Fatty acids profile of BS $\times$ BS, BS $\times S, S \times S$ and $S \times B S$ pigs.

\begin{tabular}{|c|c|c|c|c|c|c|}
\hline Item & $B S \times B S$ & $B S \times S$ & $S \times S$ & $S \times B S$ & SEM & $\overline{p \text {-value }}$ \\
\hline C14: $0, \%$ & 1.44 & 1.46 & 1.65 & 1.62 & 0.04 & 0.25 \\
\hline C16: $0, \%$ & $24.02^{b}$ & $25.03^{\mathrm{ab}}$ & $25.83^{a}$ & $26.53^{a}$ & 0.33 & 0.02 \\
\hline C16: 1, \% & 3.17 & 3.35 & 3.52 & 3.35 & 0.10 & 0.69 \\
\hline C17: $0, \%$ & 0.15 & 0.14 & 0.14 & 0.12 & 0.004 & 0.14 \\
\hline C18: $0, \%$ & 12.18 & 12.38 & 13.38 & 13.78 & 0.27 & 0.10 \\
\hline C18: 1n-9t, \% & $0.12^{\mathrm{a}}$ & $0.10^{\mathrm{b}}$ & $0.10^{\mathrm{b}}$ & $0.10^{\mathrm{b}}$ & 0.003 & 0.03 \\
\hline C18: $1 n-9 c, \%$ & 38.57 & 40.25 & 39.18 & 40.55 & 0.50 & 0.47 \\
\hline C18: 2n-6c, \% & $14.72^{\mathrm{a}}$ & $12.33^{\mathrm{ab}}$ & $11.58^{b}$ & $10.18^{b}$ & 0.59 & 0.02 \\
\hline C20: $0, \%$ & $0.16^{b}$ & $0.19^{a}$ & $0.18^{\mathrm{ab}}$ & $0.20^{\mathrm{a}}$ & 0.01 & 0.03 \\
\hline $\mathrm{C} 20: 1, \%$ & 0.63 & 0.72 & 0.70 & 0.75 & 0.02 & 0.36 \\
\hline C18: $3 n-3, \%$ & $0.54^{a}$ & $0.39^{b}$ & $0.42^{\mathrm{ab}}$ & $0.40^{\mathrm{b}}$ & 0.02 & 0.04 \\
\hline C20: 2, \% & 0.42 & 0.35 & 0.38 & 0.33 & 0.02 & 0.17 \\
\hline C20: $3 n-6, \%$ & 0.38 & 0.36 & 0.34 & 0.25 & 0.02 & 0.16 \\
\hline C20: $4 n-6, \%$ & $3.37^{a}$ & $2.90^{a}$ & $2.47^{\mathrm{ab}}$ & $1.78^{b}$ & 0.21 & 0.03 \\
\hline $\mathrm{SFAs}^{\dagger}, \%$ & $37.97^{c}$ & $39.19^{b c}$ & $41.16^{\mathrm{ab}}$ & $42.25^{\mathrm{a}}$ & 0.60 & 0.02 \\
\hline MUFAs ${ }^{\ddagger}, \%$ & 42.49 & 44.42 & 43.49 & 44.75 & 0.48 & 0.31 \\
\hline PUFAs§ ${ }^{\S} \%$ & $19.56^{a}$ & $16.37^{\mathrm{ab}}$ & $15.30^{\mathrm{b}}$ & $13.03^{b}$ & 0.84 & 0.02 \\
\hline UFAs", \% & $620.05^{a}$ & $60.78^{a b}$ & $58.79^{b}$ & $57.78^{b}$ & 0.60 & 0.02 \\
\hline SFAs + MUFAs, $\%$ & $80.46^{b}$ & $83.61^{\mathrm{ab}}$ & $84.65^{\mathrm{a}}$ & $87.00^{\mathrm{a}}$ & 0.84 & 0.02 \\
\hline PUFAs/SFAs & $0.52^{\mathrm{a}}$ & $0.42^{\mathrm{ab}}$ & $0.38^{b}$ & $0.31^{b}$ & 0.03 & 0.01 \\
\hline
\end{tabular}

a-c Within a row, values with different superscript letters differ $(P<0.05)$.

tSFAs $=\mathrm{C} 14: 0+\mathrm{C} 16: 0+17: 0+\mathrm{C} 18: 0+\mathrm{C} 20: 0$.

¥MUFAs $=\mathrm{C} 16: 1+\mathrm{C} 18: 1 \mathrm{n}-9 \mathrm{t}+\mathrm{C} 18: 1 \mathrm{n}-9 \mathrm{c}+\mathrm{C} 20: 1$.

\$PUFAs $=C 18: 2 n-6 c+C 18: 3 n-3+C 20: 2+C 20: 3 n-6+C 20: 4 n-6$.

IUFAs $=$ MUFAs + PUFAs.

line with earlier investigations in Chinese indigenous and foreign pig breeds (Dostálová et al., 2020; Franco et al., 2014; Huang et al., 2020; Jiang et al., 2011), hinting that there is a certain pattern in FAs composition. It is well known that FAs composition is closely related to pork quality, nutritional value and shelf life of meat. From the point of view of pork quality, SFAs and MUFAs are generally positively associated with eating quality including flavor, tenderness and juiciness, while PUFAs is negatively correlated with eating quality (Cameron et al., 2000; Cameron and Enser 1991). In the present study, BS $\times$ BS pigs had the lowest SFAs content, MUFAs content and the highest PUFAs content and $\mathrm{S} \times \mathrm{BS}$ pigs presented the exact opposite phenomenon, albeit not all the differences reached statistical significance. This finding implied that the eating quality of BS $\times$ BS pigs may have potential inferiority. In regard of nutritional value and human health, the increase in PUFAs intake is beneficial for lowering the risk of cardiovascular diseases (Scollan et al., 2017). BS $\times$ BS pigs had the highest PUFAs content provided the idea that BS $\times$ BS pigs could be used to develop functional pork products. In addition, the PUFAs/SFAs value in foodstuff is an important measure of the relative risk factor of the cholesterol content and cardiovascular diseases (Heck et al., 2017; Xiong et al., 2017). The higher the ratio, the healthier a foodstuff is considered and the recommended daily allowance of PUFAs/SFAs for human is greater than 0.45
(Hoffman et al., 2013). The ratio in BS $\times$ BS pigs was 0.52 , thus we can think of the meat being a healthy byproduct. However, UFAs is susceptible to oxidation, leading to the development of rancidity and reduction of shelf life of meat (Wood et al., 2004). As described above, all these findings supported the conclusion that the meat of $B S \times B S$ pigs is helpful for human health with advanced nutritional value, but at the expense of eating quality and shelf life.

\section{CONCLUSION}

BS $\times$ BS pigs exhibited superior growth rate and carcass performance. In addition, each pig breed possessed desirable meat quality, as evidenced by moderate $\mathrm{pH}$, color score, IMF content and shear force value, among which the performance of $S \times$ BS pigs was prominent. Take account of the contents of SFAs, MUFAs, PUFAs and the PUFAs/ SFAs value, the eating quality of $S \times B S$ pigs was favorable and the meat of BS $\times$ BS pigs, by contrast, was helpful for human health with advanced nutritional value. In light of the importance of growth performance, carcass characteristics and meat quality in pig industry, BS $\times$ BS pig breed is more effective for commercial development of Shaziling pigs and providing healthy pork products.

\section{ACKNOWLEDGEMENT}

The research was supported by the Key Research and Development Program of Hunan Province (2019NK2193, 
Evaluation of Growth Performance, Carcass Characteristics and Meat Quality of Shaziling Pigs and its Hybrids Crossbred...

2020NK2024), Open Research Program of Hunan Provincial Key Laboratory (2017TP1030) and Modern Swine Industry Technology System of Hunan Province.

\section{Conflict of interest}

The authors declare that there is no conflict of interest.

\section{REFERENCES}

Cameron, N.D. and Enser, M.B. (1991). Fatty acid composition of lipid in longissimus dorsi muscle of Duroc and British Landrace pigs and its relationship with eating quality. Meat Science. 29: 295-307.

Cameron, N.D., Enser, M., Nute, G.R., Whittington, F.M., Penman, J.C., Fisken, A.C., Perry, A.M., Wood, J.D. (2000). Genotype with nutrition interaction on fatty acid composition of intramuscular fat and the relationship with flavour of pig meat. Meat Science. 55: 187-195.

Chen, C., Zhu, J., Ren, H.B., Deng, Y., Zhang, X., Liu, Y.Y., Cui, Q.M., Hu, X.G., Zuo, J.B., Chen, B., Zhang, X., Wu, M.S., Peng, Y.L. (2021). Growth performance, carcass characteristics, meat quality and chemical composition of the Shaziling pig and its crossbreeds. Livestock Science. 244: 104342.

Chen, G.S., Chen, S., Sui, Y.N. (2016). Effect of slaughter weight on production and meat quality of Juema pig. Indian Journal of Animal Research. 50: 588-594.

Corlett, M.T., Pethick, D.W., Kelman, K.R., Jacob, R.H., Gardner, G.E. (2021). Consumer perceptions of meat redness were strongly influenced by storage and display times. Foods. 10: 540 .

Dostálová, A., Svitáková, A., Bureš, D., Vališ, L., Volek, Z. (2020). Effect of an outdoor access system on the growth performance, carcass characteristics and longissimus lumborum muscle meat quality of the Prestice Black-Pied pig breed. Animals (Basel). 10: 1244.

Franco, D., Vazquez, J.A., Lorenzo, J.M. (2014). Growth performance, carcass and meat quality of the Celta pig crossbred with Duroc and Landrace genotypes. Meat Science. 96: 195-202.

Gopinathan, A. and Usha, A.P. (2011). Comparative evaluation of growth and carcass traits in Large White Yorkshire, Desi and their crossbred pig. Indian Journal of Animal Research. 45: 203-206.

Guo, Y.M., Li, L.Y., Lai, Z.S., Huang, L.B., Huang, Z.Y., Tu, J.M., Qiu, H.Q., Huang, L.S., Xiao, S.J. (2017). Present status and prospect of utilization of indigenous pig breeds in China. Acta Agriculturae Universitatis Jiangxiensis. 39: 427-435. (in Chinese)

Heck, R.T., Vendruscolo, R.G., de Araújo Etchepare, M., Cichoski, A.J., de Menezes, C.R., Barin, J.S., Lorenzo, J.M., Wagner, R., Campagnol, P.C.B. (2017). Is it possible to produce a low-fat burger with a healthy $n-6 / n-3$ PUFA ratio without affecting the technological and sensory properties? Meat Science. 130: 16-25.

Hoffman, L.C., Laubscher, L.L., Leisegang, K. (2013). Nutritional value of cooked offal derived from free-range rams reared in South Africa. Meat Science. 93: 696-702.
Huang, Y.Z., Zhou, L.S., Zhang, J.J., Liu, X.X., Zhang, Y.F., Cai, L.P., Zhang, W.C., Cui, L.L., Yang, J., Ji, J.X., Xiao, S.J., Ai, H.S., Chen, C.Y., Ma, J.W., Yang, B., Huang, L.S. (2020). A large-scale comparison of meat quality and intramuscular fatty acid composition among three Chinese indigenous pig breeds. Meat Science.168: 108182.

Ilavarasan, R. and Abraham, J.J. (2018). The meat quality attributes and nutritional composition of three way synthetic pigs meat as influenced by age at slaughter. Indian Journal of Animal Research. 52: 464-469.

Jiang, Y.Z., Zhu, L., Li, X.W., Si, T. (2011). Evaluation of the Chinese indigenous pig breed Dahe and crossbred Dawu for growth and carcass characteristics, organ weight, meat quality and intramuscular fatty acid and amino acid composition. Animal. 5: 1485-1492.

Keenan, D.F. (2016). Encyclopedia of food and health: pork meat quality, production and processing on ( $1^{\text {st }}$ ed.). Oxford (UK): Academic Press.

Latimer, G.W. (2012). Official methods of analysis of AOAC International (19th ed.). Gaithersburg, MD: AOAC International.

Lee, S.H., Choe, J.H., Choi, Y.M., Jung, K.C., Rhee, M.S., Hong, K.C., Lee, S.K., Ryu, Y.C., Kim, B.C. (2012). The influence of pork quality traits and muscle fiber characteristics on the eating quality of pork from various breeds. Meat Science. 90: 284-291.

Li, Y.H., Liu, Y.Y., Li, F.N., Lin, Q., Dai, Q.Z., Sun, J.B., Huang, X.G., Chen, X.A., Yin, Y.L. (2018). Effects of dietary ramie powder at various levels on carcass traits and meat quality in finishing pigs. Meat Science. 143: 52-59.

Liu, Y.Y., Li, F.N., He, L.Y., Tan, B.E., Deng, J.P., Kong, X.F., Li, Y.H., Geng, M.M., Yin, Y.L., Wu, G.Y. (2015). Dietary protein intake affects expression of genes for lipid metabolism in porcine skeletal muscle in a genotypedependent manner. British Journal of Nutrition. 113: 10691077.

Scollan, N.D., Price, E.M., Morgan, S.A., Huws, S.A., Shingfield, K.J. (2017). Can we improve the nutritional quality of meat? Proceedings of the Nutrition Society. 76: 603-618.

Touma, S. and Oyadomari, M. (2020). Comparison of growth performances, carcass characteristics and meat qualities of Okinawan indigenous Agu pigs and crossbred pigs sired by Agu or Duroc boar. Animal Science Journal. 91: e13362.

Wood, J.D., Richardson, R.I., Nute, G.R., Fisher, A.V., Campo, M.M., Kasapidou, E., Sheard, P.R., Enser, M. (2004). Effects of fatty acids on meat quality: A review. Meat Science. 66: 21-32.

Xiong, G.Y., Gao, X.Q., Zheng, H.B., Li, X., Xu, X.L., Zhou, G.H. (2017). Comparison on the physico-chemical and nutritional qualities of normal and abnormal colored fresh chicken liver. Animal Science Journal. 88: 893-899.

Yang, H., Xu, X.L., Ma, H.M., Jiang, J. (2016). Integrative analysis of transcriptomics and proteomics of skeletal muscles of the Chinese indigenous Shaziling pig compared with the Yorkshire breed. BMC Genetics. 17: 80. 